\title{
CLINICO PATHOLOGICAL STUDY OF ACANTHOSIS NIGRICANS AND ITS CORRELATION WITH OBESITY AND INSULIN RESISTANCE
}

\author{
Krishnakanth ${ }^{1}$, Anandan. $S^{2}$, Gayathri. $R^{3}$, Adikrishnan. $S^{4}$, Murugan. $S^{5}$, Sudha. $R^{6}$, Mahalakshmi. $V^{7}$
}

\begin{abstract}
${ }^{1}$ Associate Professor, Department of Dermatology Sri Ramachandra Medical College and Research Institute. 2Professor, Department of Dermatology Sri Ramachandra Medical College and Research Institute. ${ }^{3}$ Senior Resident,Department of Dermatology Sri Ramachandra Medical College and Research Institute. ${ }^{4}$ Associate Profesor, Department of Dermatology Sri Ramachandra Medical College and Research Institute. 5 Professor, Department of Dermatology Sri Ramachandra Medical College and Research Institute. ${ }^{6}$ Professor, Department of Dermatology Sri Ramachandra Medical College and Research Institute. 7Professor, Department of Dermatology Sri Ramachandra Medical College and Research Institute.
\end{abstract}

\begin{abstract}
Acanthosis nigricans being a dermatologic marker of a metabolic disease, the dermatologist has an important role in identifying the subset of obese patients with acanthosis nigricans who are at a greater risk of consequent atherosclerotic cardiovascular disease. The objective of the study was to compare the serum Insulin levels and the Insulin sensitivity indices between obese and non-obese acanthotics and to compare the epidermal thickness and anthropometric measurements between the two groups. Thirty patients with biopsy proven acanthosis nigricans were included in the study. Ten patients of other dermatological complaints were included as control group. The serum Insulin levels and the Insulin sensitivity indices (Quantitative Insulin Sensitivity Check Index and Homeostasis Model Assessment of Insulin resistance Index) were compared between obese and nonobese acanthotics along with Epidermal thickness (Morphometric analysis) and Anthropometry measurements.(Body Mass Index and Waist to Hip ratio). Significant difference in the mean values of serum Insulin levels and Insulin sensitivity indices were noted between obese and non-obese acanthotics. Significant positive correlation of Epidermal thickness and Anthropometric measurements was also present between the disease and control group. This study confirms that Acanthosis Nigricans is a Reliable Cutaneous marker of Hyperinsulinemia. Epidermal thickness and anthropometric measurements parallels the same.
\end{abstract}

KEYWORDS: Insulin Diabetes Resistance Acanthosis Nigricans Obesity.

HOW TO CITE THIS ARTICLE: Krishnakanth, Anandan. S, Gayathri. R, Adikrishnan. S, Murugan. S, Sudha. R, Mahalakshmi. V . "Clinico Pathological Study of Acanthosis Nigricans and its Correlation with Obesity and Insulin Resistance". Journal of Evolution of Medical and Dental Sciences 2015; Vol. 4, Issue 90, November 09; Page: 15566-15577, DOI: 10.14260/jemds/2015/2233.

INTRODUCTION:The skin often a window to systemic diseases. A variety of cutaneous manifestations have been identified that often reflect the presence and course of systemic disorders. The ability to recognize those that may indicate an underlying serious disorder is of particular importance, in preventing the complications.Acanthosis Nigricans, is one such manifestation that serves as the dermatologic marker of metabolic disease, especially insulin resistance and less frequently of a internal malignancy. The severity of acanthosis nigricans correlates with the degree of insulin concentrations.Acanthus (Greek= thorn) and Nigricans (Latin=becoming black). ${ }^{1}$ is a symmetric eruption characterized by hyperpigmented, velvety plaques, more commonly over the flexures of the body including the neck, axillae, groin, umbilicus, antecubital and popliteal fossae. ${ }^{2}$ occasionally it involves the oral oesophageal, pharyngeal, laryngeal, conjuctival and anogenital mucosae.3,4,5,6,7 On the skin, hyperpigmentation and papillomatosis are usually evident and on the mucosal surfaces papillomatosis is more common thanhyperpigmentation. ${ }^{8}$

Financial or Other, Competing Interest: None.

Submission 15-10-2015, Peer Review 16-10-2015,

Acceptance 26-10-2015, Published 09-11-2015.

Corresponding Author:

Dr. Krishnakath $M$,

123, \#1 Vellala Street, Purasawkkam

Chennai-84.

E-mail: krishnakanthmurlidhar@gmail.com

DOI:10.14260/jemds/2015/2233.
Most patients with acanthosis nigricans have either clinical or sub clinical insulin resistance.9,10 The insulin resistance state is associated with several manifestations e.g. impaired glucose tolerance/diabetes mellitus, hypertension, dyslipidemia, disorder of blood coagulation, accelerated atherogenesis, ovarian thecal hyperplasia and functional hyperandrogenism. ${ }^{11}$ Measures to counter insulin resistance may delay or prevent these manifestations. The importance of acanthosis nigricans is that often it is marker of the diabetes mellitus. The early recognition of which prevents longterm complications.

Obesity is a major significant risk factor for the development of hyperinsulinemia and acanthosis nigricans. As the frequency and degree of obesity increase in the population, a concommitant increase in acanthosis nigricans can be expected. 12 The normal skin is $1.8 \mathrm{~m} 2$ and weighs approximately 4 to $5 \mathrm{~kg}$ in an average $70 \mathrm{~kg}$ man. In acanthosis nigricans there is both clinical and histopathological, increase in the thickness of skin evidenced by hyperkeratosis and irregular spiky papillomatosis. ${ }^{13-15}$

With this background, the present study is being done to estimate the insulin sensitivity of a group of patients with clinically suspected and biopsy proven acanthosis nigricans and to compare the insulin sensitivity indices between obese andnon-obese acanthotics. Currently no literature is available correlating the epidermal thickness with anthropometric measurements andinsulin sensitivity indices, therefore an attempt was made to find the relationship between them. 


\section{AIMS OF THE STUDY:}

1. To compare the serum insulin levels and insulin sensitivity indices between obese and non-obese patient with acanthosis nigricans.

2. To find the association between epidermal thickness and serum insulin levels/ insulin sensitivity indices.

3. To find the association between.

a. Anthropometry measurements and serum insulin/insulin sensitivity indices.

b. Epidermalthickness and anthropometry measurements.

AETIOLOGY AND PATHOGENESIS: Insulin is a protein hormone that is synthesized, stored, and secreted by the Islets of Langerhan in the pancreas, is responsible for regulating glucose concentrations in the blood and is released in response to the presence of glucose in the blood The target tissues are primarily the liver, triglyceride synthesis in adipose tissue, and protein synthesis in muscle.16-18 If insulin production is not stimulated, blood glucose will not be lowered and hyperpglycemia results. Fasting hyperpglycemia suggests the diagnosis of diabetes mellitus.

Insulin levels can be useful in evaluating patients with fasting hypoglycemia, in determining insulin resistance in general population, and in assessing abnormalities in beta cell secretary function and hence are used in studying the pathophysiology of diabetes. ${ }^{19}$ Although the precise basis for the development of Aconthosis Nigricans (AN) remains unclear, there is ample evidence to implicate and etiologic role of insulin. ${ }^{20-22}$ in the absence of underlying malignancy.

At normal concentrations, insulin binds preferentially to classical receptors through which it transduces effects on glucose metabolism. But at higher concentrations, it has a greater affinity to bind to the insulin like growth factor receptors, which are expressed in the skin by fibroblasts and keratinocytes and promotes its effects on cellular proliferation. ${ }^{23}$

Malignant a most likely results from the secretion of tumour products with insulin like growth factor activity at the cell receptor level. Transforming growth factor alpha is also postulated to have a role in its pathogenesis. ${ }^{24}$ Tumour products appear to be the cause of malignant acanthosis nigricans.

Obese individuals are mostly likely to have reduced affinity of the classical receptors for insulin and or postreceptor defects. A reduced number of functional receptors probably initially causes Insulin resistance with obesity, but a post-receptor defect ultimately becomes dominant. Obese acanthotics may be more severely insulin resistant than their non-acanthotic counterparts.

\section{EPIDEMIOLOGY}

Age Incidence: Lesions of acanthosis nigricans may be present at any age, 3 including at birth, occur during puberty or early adulthood. Stuart et al., ${ }^{25}$ identified acanthosis nigricans in $7.1 \%$ of 1412 children of sixth and eighth grades in a public school. Malignant AN is much rarer and occurs in elderly patients. However younger patients with malignant AN have been described, usually in association with gastric cancer.

Sex Incidence: Studies have shown that incidence by sex is roughly equal.
Race: The prevalence in caucasians is less than $1 \%$. In Hispanics prevalence is $55 \% .^{1}$ There is increased incidence in native Americans and African Americans (13.3\%), especially in children. ${ }^{2}$ It is interesting to note that there is no sex or racial propensity observed with malignant AN.

Obesity: Prevalence is $66 \%$ in adolescents who weighed more than $200 \%$ of ideal weight. Hud et al., ${ }^{26}$ observed this dermatoses in $74 \%$ of 34 patients in an adult obese population. Black obese patients were more likely to have acanthosis nigricans that white obese ones.

Hyperandrogenism: Dunaif A et al.,27documented that in a study of women without diabetes found AN only in obese, hirsute, hyperandrogenic women. Vulval acanthosis nigricans was seen in about $56 \%$ of hirsute hyperandrogenic women with insulin resistance. The axillae were involved in $33 \%$ and $30 \%$ had neck involvement. ${ }^{28}$

TYEPES OF ACANTHOSIS NIGRICANS: There are 8 types of acanthosis nigricans described in literature. ${ }^{29}$

1. BenignAN:Curth.$^{30}$ describedthisraregenodermatosesan dheproposed thatitisfamilial,inheritedasautosomaldomi nanttraitwithvariablephenotypicpenetrance,startsasaun ilaterallesionsatbirthorinearlychildhoodincreasesuntilp uberty,afterwhichitremainsstationaryordecreases.Obesi tyisnotconsideredasasignificantfactorinbenignAN.

2. Obesity associated AN: (Pseudo AN). ${ }^{31}$ : Most common type of AN, can appear at any age but are more common in adulthood. This dermatoses is weight dependent and lesions regresses completely with weight loss. A positive correlation exists between the development of acanthosis nigricans and severity of obesity.

3. Syndromic AN: Various syndromes and conditions have been associated with acanthosis nigricans. There are:

(a)Syndromes associated with Insulin resistance:

- Type A syndrome (HAIR- AN syndrome).

- Type B syndrome.

- Alstrom syndrome.32

- Lawrence-Seip syndrome.33

- Rabson-mendenhall syndrome.34

- Lipoatrophic diabetes. ${ }^{35}$

- $\quad$ Prader-Willi syndrome. 35

- Laurence-Moon-Bardet-Biedel syndrome. ${ }^{35}$

- Donohue syndrome (Leprachaunism). ${ }^{36}$

\section{(b)Other associated syndromes}

- Bloom syndrome. ${ }^{37}$

- Capozucca syndrome.

- Costello syndrome.38

- Crouzon syndrome ${ }^{39}$

- Barter syndrome.

- Cushing's syndrome.

- Hirschowitz syndrome. ${ }^{40}$

\section{(c) Associated conditions}

- Obesity

- Hypothyroidism ${ }^{41}$

- Acromegly ${ }^{41}$

- Gigantism 
- Diabetes mellitus

- Hypertension

- Hashimoto thyroiditis ${ }^{41}$

- Dermatomysitis ${ }^{54}$

\section{MATERIALS AND METHODS:}

PLACE OF STUDY: Dermatology Out Patient Department of Sri Ramachandra Medical College and Research Institute.

Period of Study: June 2013-September 2014

\section{STUDY POPULATION:}

Disease Group: Thirty patients of acanthosis nigricans of all age groups and of either sex who attend dermatology opd.

Control Group: Ten patients of all age group and of either sex group and of either sex who attend dermatology out patient department for other dermatologic complaints.

\section{Inclusion Criteria:}

Disease Group: All untreated patients of Acnathosis Nigricans.

Control Group: Patients with other dermatologic complaints. The data was collected by using two questionnaires specially designed for the study and control groups.

STATISTICAL ANALYSIS: Was done with the help of software package called SPSS/V-4.0 and SPSS/V-10. The level of significanve was fixed at $5 \%(\mathrm{P}<0.05)$. students independent $\mathrm{t}-$ test and Fishers' exact test (2-tailed) were employed to calculate the p-value. Pearsons' correlation analysis and linear regression analysis were employed to find the significant associations.

METHOD: In group I (Disease Group) 30 patients (21 females, 9 males) with biopsy proven AN and Group II (Control Group) 10 patients ( 5 females, 5 males) with other dermatological complaints were included in this study, after an informed consent.

HISTORY: All patients were questioned in details regarding the occupation, lifestyle, onset, duration, mode of progression $\&$ associations of the disease (symptoms of autoimmune and hyperandrogenism) \& sequelae of insulin resistance i.e. diabetes mellitus, hypertension etc. A detailed menstrual history was elicited from female patients.

EXAMINATION: All the subjects underwent a detailed physical examination (sites of involvement \& associated findings) including recording of vitals (pulse rate \& blood pressure) and Anthropometry measurements-heights (meters), weight (kgs), waist circumference in $\mathrm{cms}$ (at the level of umbilicus), hip circumference in $\mathrm{cms}$ (at the level of widest part of buttocks). All the findings were recorded using a specially designed proforma.From these data-Body Mass Index, BMI (kilograms per square meter) and Waist to Hip Ratio were calculated (WHR, mts)

\section{BMI (QUETELET INDEX):42}

Average (normal) $=18.5-25.0$

Overweight $=25.0-29.9$

Obesity $\geq 30$
WHR; 43 Male $>1.0$

Female $>0.8$

LABORATORY METHODS: Apart from routine blood and urine examinations, special investigations were carried to rule out associated autoimmune disease and internal malignancy. After 12 hour overnight fast, plasma glucose (mg per liter) and serum insulin levels (international units $/ \mathrm{ml}$ ) were estimated.

ASSAYS: Plasma glucose levels were measured by the end point method (Bayer's). Serum insulin levels were estimated by automated Chemilumenesce system 180 test/hour (Bayer's) with inter assay and intra assay coefficient of $5.8 \%$ and $8.0 \%$ respectively

EVALUATION OF INSULIN RESISTANCE/SENSITIVITY: Although there are many methods to estimate the insulin resistance/sensitivity, including the gold standard euglycemic hyperinsulinemic clamp technique ${ }^{44}$ and other sensitivity indices, derived from oral glucose tolerance tests (composite, Stumvoll, Belfiore, Cederholm, Gutt, Matsuda), the previous studies have shown that these methods are laborious, expensive and not satisfactory, which limited its use in clinical practice. ${ }^{45-49}$

So, we used the Quantitative Insulin Sensitivity Check Index (QUICKI) Proposed By Katz Et Al.63 And So, We Used The Quantitative Insulin Sensitivity Check Index (QUICKI) Proposed By Katz Et Al. ${ }^{50}$ And Homeostasis Model Assesment Of Insulin Resistance Index (Homa-Ir) which have been reported to be useful and easy estimate of insulin sensitivity. However, some limitations of these tests must be considered. ${ }^{51}$ Both HOMA-IR and QUICKI are indirect methods that depends on fasting plasma insulin values.

In the previous studies the correlation between the insulin sensitivity index (ISI) obtained from the OGTT (ISI oGTT $_{\text {) }}$ and those obtained from glucose clamp study is designed for measuring peripheral glucose responses during the OGTT are the results of peripheral glucose utilization and hepatic glucose production. 52 The product of fasting insulin (for HOMA) or summation of log fasting glucose and log fasting insulin (for QUICKI) therefore provides a measure of hepatic sensitivity rather than peripheral insulin sensitivity. ${ }^{53}$

Index Equation Reference

[1] QUICKI = 1119

Log fasting insulin + Log fasting glucose

[2] HOMA-IR= Fasting insulin $\times$ Fasting glucose 120

\section{5}

SKIN BIOPSY- FIG 12: A biopsy is the process by which a part or whole of the suspected disease tissue is obtained for microscopic and/or other investigations.

Local anaesthesia was given circumferentially around the lesion rather than below the lesion, so that tissue architecture was not disturbed.In this study a skin biopsy was done in all 30 subjects of Group I and the site selected being the posterior aspect of the neck in all the subjects.

FIXATION AND PROCESSING: The specimen was fixed in 10\% formalin immediately and submitted to Department of Pathology, SRMC \& RI (DU), for further processing and Haemotoxylin and Eosin staining. The stained slide was 
mounted on the light microscope (Olympus $\mathrm{CH} 30$ ) and examined under low power $(10 \mathrm{X})$, to:

1. Confirm the clinical diagnosis of AN.

2. Measurement of epidermal thickness by using the Morphometric GRID.

\section{MORPHOMETRIC GRID- FIG 13}

It is a pre-calibrated grid with

Markings ranging from $0,10,20, \ldots 100$.

1 unit $=100$ microns.

1 unit is made up of 10 sub units.

1 sub unit $=10$ microns.

1. Confirmation of the clinical diagnosis was made by studying the characteristic histopathological features.

2. Measurement of epidermal thickness:

- Each slide was analyzed for the areas of hyperkeratosis \& papillomatosis and randomly four sites were selected.

- $\quad$ Each site consists of an area of finger like upward projection of dermal papillae (elevation) and the corresponding downward elongation of rete ridge (Depression).

- Each of them were further divided into Stratum corneum (consisting of loose, basket weave orthokeratosis) and stratum malphigi (spinal, squamous and basal layers).

- Thickness of these layers were measured using the grid and recorded as follows;

\section{SITE 1:}

Upward projection (Dermal papillae)

$=$ Stratum corneum $(\mathrm{a})+$ stratum malphigi $(\mathrm{b})=(\mathrm{a}+\mathrm{b})=\mathrm{T} 1$

Downward elongation (rete ridge)

$=$ Stratum corneum $(\mathrm{c})+$ stratum malphigi $(\mathrm{d})=(\mathrm{c}+\mathrm{d})=\mathrm{T} 2$

MEAN $=\mathrm{T} 1+\mathrm{T} 2 / 2=\mathrm{W}$

Similar recordings were made from site $2 \& 3 \& 4$, and their mean values were calculated.

SITE 2: $\mathrm{T} 3+\mathrm{T} 4 / 2=\mathrm{X}$

SITE 3: T5 $+\mathrm{T} 6 / 2=\mathrm{Y}$

SITE $4: \mathrm{T} 7=\mathrm{T} 8 / 2=\mathrm{Z}$

TOTAL THICKNESS (each slide) $=\mathrm{w}+\mathrm{x}+\mathrm{y}+\mathrm{z}=------$ microns.

DISCUSSION: Acanthosis Nigricans (AN) is one of the common dermatologic problem encountered in our day to day practice and it is not simply a benign skin disorder that can be casually dismissed. The presence of obesity should initiate a search for AN. It is suggested that most, if not all patients with AN have either clinical or subclinical insulin resistance.9,10 Insulin is most often implicated as the cause of acanthosis nigricans with out underlying malignancy. ${ }^{29}$ Recently, it has been proposed that AN could be considered as a new cutaneous marker of severe atopic dermatitis and a common sign in Down's syndrome. ${ }^{54}$

AN unassociated with malignancy may be present at birth or occur during puberty or early adulthood, although it can occur any age. ${ }^{54}$ Many studies have shown increase prevalence of $\mathrm{AN}$ in school going children. ${ }^{25}$ In the present study it was observed that majority of the patients belonged to the $2^{\text {nd }}$ and $3^{\text {rd }}$ decades. The youngest age to manifest in our study was $10 \mathrm{yrs}$ and the oldest $60 \mathrm{yrs}$. $26.6 \%$ of our patients were between 20-30 yrs. (TABLE 1; FIGURE 1)

As for as the age of onset (TABLE-2; FIGURE 2) is concerned, we noticed a maximum number of patients in the age group of $10-19$ yrs (33.3\%), followed by $2^{\text {nd }}$ and $3^{\text {rd }}$ decades. This observation is consistent with the results of Stuart $\mathrm{CA}^{25}$ and Hud et al. ${ }^{26}$ Although Stuart CA, et al., ${ }^{25}$ observed that the incidence by sex was roughly equal, In present study there were more females $(70 \%)$ than males (30\%)-TABLE 3; FIG 3.

The over all prevalence of AN was higher in clearly mentioned in study done by Varthakavi PK, et al.,9 Females preponderance could be explained by the fact that obesity is another determinant of Insulin resistance and In almost all population more women are obese or overweight than men. ${ }^{55}$ But in our study there is no statistically significant difference in proportion of obesity between males and females ( $p$ value $=$ 0.69).

Patients with clinically evident AN were almost always obese, out of 30 Patients of Disease Group (Group 1) 17(11 female and 6 male) subjects had increased Body Mass Index (BMI) (32.9 \pm 6.2$)$ and 13 (10 female and 30 males) subjects had normal BMI $(27.4 \pm 2.1)$ than that of the control group (Group II) were all the 10 patients had normal BMI $(24.7 \pm 3.1)$, which was statistically significant (P-value $<0.0001$ ), (Table -3).

All control subjects had a Waist Hip Ratio (WHR) $<1.0 .63 .3 \%$ females with acanthosis nigricans had WHR upto $1.06 .6 \%$ had ratio $>1.1$ whereas $26.6 \%$ of the males had a WHR $<1.0$ and $3.3 \%$ had a WHR>1.1. There was no significant positive correlation of WHR between controls and obese and non-obese patients of acanthosis nigricans. (Table-5) Significantly $41.6 \%$ of normal BMI had increased WHR, especially in female population.

This implies that the distribution of body fat was abnormal in spite of a normal BMI. There was significant positive correlation with BMI between obsese and non obese acanthotics but not with WHR. Similar finding was observed in a study conductedby Varthakavi PK et al. ${ }^{9}$ When compared with controls $(109 \pm 3.7)$ all patients with AN had significantly higher levels of Insulin $(26.7 \pm 15.5)$ and the significant groups at $5 \%$ level were between obese acanthosis and control subjects (Table-5). Out of 30 patients with AN 12 subjects had increased fasting serum insulin level. Out of which 9 patients obese.

Studies have shown that AN is a independent variable and does not depend on the indices of adiposity having increased Sr.insulin levels. ${ }^{56}$ Fasting insulin per se provides and approximate measure of insulin sensitivity, but it is not felt to be very precise. ${ }^{57}$ So various insulin resistant indices are calculated. The euglycemic clamp technique is the gold standard, but it is laborious and expensive. So an easy measure of peripheral insulin sensitivity is calculated by using fasting glucose $(\mathrm{mg} / \mathrm{dL})$ to insulin $(\mu \mathrm{U} / \mathrm{ml})$ ratio.

A value of less than 5 is considered significant. 58 Thus patients with insulin resistance have raised fasting serum insulin levels $(>25 \mu / \mathrm{ml})$ and lower glucose to insulin ratio $(<5)$. Significantly in this study 12 out of 30 patients have glucose to insulin ratio of less than 5.Patients with AN were significantly insulin resistant than the controls, with obese acanthosis being more severely insulin resistant that their non-acanthotic controls. This coincides well with many studies confirming that AN is associated with a significant insulin resistance. ${ }^{59-60}$ 
All patients with increased waist-to hip ratio also had increased serum insulin levels. When we correlated the serum insulin levels and Insulin resistance indices (QUICKI and HOMA-IR) to indices of adiposity (BMI amd WHR),there was a positive significant correlation of WHR to serum insulin levels ( $\mathrm{p}$ value $=0.01$ ) and QUICKI ( $\mathrm{p}$ value $=0.047$ ), but the $\mathrm{p}$ value was not significant between BMI and serum insulin levels (0.20). ${ }^{61}$ (Table -4\&5). (FIG-7,8 \& 9)

Out of 30 patients only 4 patients were overtly diabetic at the time of inclusion and 10 patients had fasting plasma glucose of more than $127 \mathrm{mg} / \mathrm{dL}$. Of the 14 Diabetic patients all obese, only $8(\mathrm{~F}=5, \mathrm{M}=3)$ had increased serum insulin levels. None of the subjects in the control group had either raised fasting plasma glucose or insulin levels.

Stuart CA et al.62 and Rogers DL ${ }^{1}$ proposed that high levels of insulin that causes symptoms of hyperinsulinemia often is able to maintain glucose homeostasis in the face of insulin resistance and these patients develop Type 2 DM over a period of time, when the pancreatic B-cells get exhausted ,significantly in this study 4 patients had increased serum insulin levels with normal blood glucose.

Among 30 patients three had polycystic ovarian disease, all with increased serum insulin levels, only one patient had features of Hyperandrogenism (Hirsuitism and Clitromegaly) and one patient was non-obese. This is in consistent with the study of Cibula $D$ et al.63 Out of 8 patients $(F=7, M=1)$ of Hypothyroidism, all obese, 4 patients $(F=3, M=1)$ Had increased serum insulin levels. ${ }^{64}$

The commonest site involved was neck (100\%)( FIG 4) followed by axillae (FIG 5) (90\%). Among the other intertriginous areas of the body, groins were frequently involved, followed by anterior cubital fossae and popliteal fossae.(fig 6) No patient in this study population manifested with either generalized hyperpigmentation or mucous membrane involvement. Similar observation was made by Varthkavi PK et al. ${ }^{9}$ in which none of the 36 patients studied has mucosal involvement.

The skin in acanthosis nigricans is palpably thickened and covered by small papillomatous elevations, which gives it a velvety texture. As the thickening increases the skin lines are further accentuated and the surface becomes mammillated or rugose and larger warty excrescences develop. This is histopathologically reflected by hyperkeratosis, papillomatosis and acanthosis.

The normal thickness of stratum corneum (10um) and viable epidermis ranges from (100um-200um). ${ }^{15}$ The epidermal thickening in acanthosis nigricans was measured using the calibrated morphometric grid.All the patients in the study group had increased epidermal thickness of above 200um.Linear Regression analysis showed a significant positive correlation between epidermal thickness and serum insulin levels and insulin sensitivity indices. (FIG-10 \& 11)

Study conducted by Stuart CA et al.,62 in eighty-nine African-American subjects with AN, proposed that fasting plasma insulin concentration was in direct proportion to the severity of the AN involvement of neck.Correlation analysis of epidermal thickness and anthropometry measurements (BMI and WHR) showed there exists a significant positive correlation between epidermal thickness and waist to hip ratio $(r=0.33, p=0.040)$. However there is no significant correlation between epidermal thickness and body mass index $(r=0.25$, $\mathrm{p}=0.09$ ).

The distribution of AN according to gender and other associated conditions - TABLE- $6 \& 7$.
CONCLUSION: References in dermatology literature have discussed many syndromes and malignancy associated with acanthosis nigricans. Less emphasis is put on the most common cause of AN (i.e) hyperinsulinemia associated with obesity.Though it may be important for dermatology to recognize AN for appropriate treatment of cutaneous manifestation, it has a greater significance as a sign of systemic disease.

The dermatologist has an important role in identifying the subset of obese patients with acanthosis nigricans. These patients have hyperinsulinemia with a normal glucose which indicates a pre-diabetic condition and it pre-disposes to overt diabetes mellitus. In a developing country like India where only $10 \%$ diabetes mellitus is detected, all patients attending skin clinic should be screened for the presence of diabetes mellitus keeping in mind, the wide range of cutaneous signs associated with it.

"This study confirms that Acanthosis Nigricans is a reliable cutaneous marker of Insulin resistance, the significance of which increase in association with obesity \& diabetes mellitus and also it is evidenced that the skin changes (epidermal thickness) parallels the serum insulin levels and insulin resistant indices. Therefore, it is mandatory that when findings of acanthosis nigricans are present, anthropometry measurements (body weight, waist to hip ratio), blood glucose and fasting serum insulin should be obtained. Elevated blood insulin levels are helpful for demonstrating to patients the cause of their condition and the need for

\section{BIBLIOGRAPHY:}

1. Rogers DL Acanthosis nigricans. Semin Dermatol 1991; $10: 160-3$.

2. Pollitzer S. Acanthosis nigricans : A symptom of a disorder of the abdominal sympathetic. JAMA 1909, 53 : $1969-73$.

3. Chaung SD et al., : Familial acanthosis nigricans with madarosis.Br. J Dermatol, 1995, $133: 104$

4. Tabandeh $\mathrm{H}$ et al., : Conjunctival involvement malignancy associated acanthosis nigricans. EYE 1993, 7: 648.

5. Hall JM et al., Oral acanthosis nigricans : Report of a cae and comparison of oral nd cutaneous pathology. Am J Dermatolopathal 1988; $10: 68$

6. Kozlowaski LM, Nigra TP Esophageal acanthosis nigricans in association with adenocarcinoma from an unknown primary site. J Am Acad Dermatol $1992: 26: 348$ - 51.

7. Brown J, Winkel Mann RK. Acanthosis nigricans : A study of 90 cases. Medicine, 1968; $47: 33$ - 51.

8. Schwartz RA, Burgess GH Florid cutaneous papillomatosis. Arch Dermatol 1978:803 - 6

9. Varthakavi PK, Waingankar A, Patel KL, Wadhwa SL, Khopkar U, Sengupta RA, Merchanr PC, Mehtalia SD, Nihalan KD., : Acnathosis nigricans : A Dermatologic marker of metabolic disease. Indian J Dermatol venereal Leprol, 2002; $68: 67-72$.

10. Kahn CR, Flier JS, Bar RS. Et al.,. The syndromes of insulin resistance and acanthosis nigricans ; insulin - receptor disorders in man. N Engl J Med1979 ; 294 : 739-45.

11. Reaven GM. Role of Insulin resistance in human disease. Diabetes 1988; 37: 1595-1607. 
12. Katz AS, david C et al., : Acanthosis nigricans in obese patients. Presentations and implications for prevention of atherosclerotic vascular disease. J Natl. Med Assoc. 1998; 89 (8) : 523-7.

13. Burgdof, Huxr, Le Boit, Smith, Solomon. The Normal skin. Maize cutaneous pathology, 1998; $1: 1-2$.

14. Leider M, Bunke CM : Physical dimension of the skin. Determination of the specific gravity of skin. Hai and nail. AMA Arch. Dermatol. Syph. 1954; 69 : 563.

15. Archer CB. Function of skin. In : Rook / Wilkinson / Ebling. Text Book of Dermatology, Vol. 1. Sixth edition (Chapter 4), 115-6.

16. Sacks DB. Carbohydrates. In : Burtis CA, Ashwood, ER, Tietz textbook of clinical chemistry. $2^{\text {nd }}$ Ed. Philadelphia : WB sounders, 1994 : 935-949.

17. Dods RF. Diabetes Mellitus. In : Kaplan LA, Pesce AJ, Clinical chemistry: Theory, analysis and correlation, $3^{\text {rd }}$ edition. 1996 : 619-621.

18. Davis SN, Granner DK. Insulin, oral hypoglycemic agents, and the pharmacology of the endocrine pancreas. In : Hardman JG, Limbird LE, Goodman \& Gilman's pharmacological basis of therepeutics, $9^{\text {th }}$ ed, NY :McGraw - Hill, 1996 : 1487-98.

19. McAuley KA, Williams SM et al., Diagnosing insulin resistance in the general population. Diabetes Care : 2001; 24: (3) 460-4.

20. Flier JS et al., Acanthosis nigricans in obese women with hyperdrogenism. Charecterisation of an insulin resistant state distinct from Type A and B syndrome. Diabetes, 1985; $34: 101$.

21. Dunaif A et al., : Characterisation of groups of Hyperandrogenic women with acanthosis nigricans impaired glucose tolerance and or hyperinsulinemia. J Clin. Endocrinol Metab, 1987; 65: 499.

22. Peters EJ et al., Acanthoisis nigricans and obesity. Acquired and intrinsic effects of insulin action. Metabolism, 1986; 35: 807.

23. Flier Js. Lilly lecture syndromes of insulin resistance: from patients to gene and back again. Diabetes 1992;41 : $207-19$.

24. Ellis DL, Kafka SP, Chow JC, et al. Melanoma, growth factors, acanthoisis nigricans, the sign of lLess'er- Trelat, and multiple acrochordons : a possible role for alphatrans-forming growth factor in cutaneous paraneoplastic syndromes. N Engl J Med 1987 ; 317 : $1582-7$.

25. Stuart CA,Pate CJ, Peters EJ. Prevalance of acanthosis nigricans in an unselected population. Am J Med 1989;87;269-722

26. Hud JA, Jr. Cohen JB, Wagner JM et al., Prelevence and significance of acanthosis nigricans in an adult obese population. Arch Dermatol 1992 : 128 : 941 -4.

27. Dunaif A, Green G, Phelps RG, et al., acanthosis nigricans, insulin action and Hyperandrogenism : clinical, histoligical and biochemical findings. J Clin Endocrinol metabol, 1991; 73 : 590-5.

28. Grasinger CC.Wild RA, Parker J.Vulvar AN an marker of insulin resistance in a hirsute women. Fertile steril 1993;59;583-6.
29. Schwartz RA : Acanthosis nigricans. J Am Acad Dermatol 1994; $31: 3$.

30. Curth HO. Benign type of acanthosis nigricans : Etiology. Arch Dermatol syphilol, 1936 : 34 : 353-66.

31. Curth HO, Aschner BM. Genetic studies on acanthosis nigricans. MAM Arch Dermatol. 1959; 79 : 55-66.

32. Goldstein JL, Fialkow PJ. The alstrom syndrome : report of 3 cases. Medicine, 1973; 52: 53-71.

33. Lawrence RD. Lipodystrophy and hepatomegaly with diabetes abd other metabolic disturbances : a case throwing new light on the action of insulin. Lancet 1946; 250 : 724-31, 773-5.

34. Rabson SM, Mendenhal EN. Familial Hypertrophy of pineal body, hyperplasia of adrenal cortex and diabetes mellitus. Report of 3 cases. am J Clin pathol 1956; $26: 283$ $-90$.

35. Reed WB, Dexter R, Croley C, et al., : Congenital lipodystrophic diabetes with acanthosis nigricans : The Seip-lawrence syndrome. Arch Dermatol, 1965; $91: 326-34$

36. Al- Gazali LI, Devadas K. A syndrome of insulin resistance resembling Leprechaunism in five sibs of consanguineous parents. JMed Genet 1993; 30: 470-5.

37. Curth HO. Bloom's syndrome associated with acanthosis nigricans. Arch Dermatol. 1964; 90 : 349-50.

38. Teebi AS. Shaabani IS. Further delineation of Costello syndrome. Am J Med Genet 1993; 47 : 166-8.

39. Kozumi H, Sato KC et al., An association of acanthosis nigricans and crouzon syndrome. J dermatol (Tokyo) 1992; 19 : 122-6.

40. Potasman I, Stermer E et al., The Groll-Hirschowitz syndrome. Clin Genet 1985; 28: 76-8.

41. Sturner RA, denning S. Marchase P. Acanthosis nigricans and autoimmune reactivity.

JAMA 1981; $246: 763-5$.

42. Garrow JS abd Webster J. Quetelets' index as a measure of fatness international journal of obesity, 1985; $9: 147$ 153.

43. World health organization, physical status ; The use abd interpretation of anthripometry measurements, Geneva, Switzerland; WHO 1995; WHO Technical Report Series.

44. Defronzo RA, Tobin JD, Andres R 1979, Glucose clamp technique : A method for quantifying insulin secretion and resistance. Am J Physical 237 ; E214-E223.

45. Matsuda M, Defronzo RA 1999. Insulin sensitivity indices obtained from oral glucose tolerance testing. Comparison with the euglycemic insulin clamp. Diabetes care $22: 1462-1470$

46. Gutt M, davis CL, Spitzer SB, Liabre MM, Kumar M, Czanecki EM, Schnierman N, Skyler JS, Marks JB 2000, Validation of the insulin sensitivity index comparison with other measures. Diabetes Res clinPract47 : 1784.

47. Stumvoll M, Mitrakou A, Pimenta W, jenssen T, YkiJarvinen H, Van Haeften T, Renn W, Gerich J 2000. Use of the oral glucose tolerance test to assess insulin release and insulin sensitivity. Diabetes care 23: 295-301.

48. Befiore F, Lannello S, Volpicelli g 1998. Insulin sensitivity indices calculated from basal and OGTT-induced insulin, glucose, and FFA levels. Mol genet Metab 63: 134-141. 
49. Cederholm J, Wibell L 1990. Insulin release and peripheral sensitivity at the oral glucose tolerance test. Diabetes Res ClinPract 10; 167-175.

50. Katz A, Nambi SS, Mather K, Baron AD, follmann DA, Sullivan G, Quon MJ 2000. Quantitative insulin sensitivity check index : a simple accurate method for assessing insulin sensitivity in humans. J clin endocrinal Metab85 ; 2402-2410.

51. Mathews Dr. Hosker JP, rudenski AS, Naylor BA, treacher DF, turner RC 1985. Homeostasis model assessment : insulin resistance and cell function from fasting plasma glucose and insulin concentrations in man. Diabetologia 28: 412-419.

52. Ferrannini E, Simonsn DC, Katz LD et al., 1988. The disposal of an oral glucose load in patients with noninsulin-dependent diabetes. Metabolism 37 : 79-85.

53. Campbell PJ, mandarino IJ, gerich JE. 1988. Quantification of the relative impairment in actions of insulin on hepatic glucose production and peripheral glucose uptake in non-insulin-dependent diabetes mellitus. Metabolism 37 : 15-21.

54. Curth HO Acanthosisnigricans. Birth Defects 1971 ; 325-327.

55. Van Itallie TB, Lew EA. Assessment of morbidity and mortality risk in the overweight patient. In : Treatment of seriously obese patient. The Guilford Press, 1992, 332.

56. Deborah young-Hyman, David G. Schlundt, Leanna Herman, et al., : Evaluation of the insulin Resistance Syndrome in 5-to 10-Year-Old Overweight/Obese African-American Children. Diabetes Care, 2001 Jul; 24(7): 1175-80.
57. Davidson MB, clinical implications of insulin resistance syndromes. Am J mMed,

199599 (4): 420-6.

58. Pierre-Henri, patric Cousin, et al., Glucose-to-Insulin Ratio rather than sex hormone-binding globulin and adiponectin levels is the best oredictor of insulin resistance in nonobese women with polycystic ovary syndrome. The journal of endocrinology \& metabolism 2003; 88(8) : 3626-3631.

59. Yamazaki, Hajime et al., Acanthosis nigricans is a reliable cutaneous marker of insulin resistance in obese Japanese children. Pediatrics iInternational 2003; 45 (6) : 701 . 705.

60. Flier JS: Metabolic importanceof acanthosis nigricans. Arch Dermatol, 1985121 : 193.

61. Mannucci, E., Bardini, G., Rotella, F. \& Rotella, C. M. (2003) Comparision among different insulin sensitivity indices in obese patients. Diabetic Medicine 20 (6), 462-466.

62. Stuart CA, Gilkison CR, Keenan BS, Nagamani M. Hyperinsulinemia and acanthosis nigricans in Africans. J Natl Med Assoc. 1997; 89 (8): 523-7

63. Cibula D, Skrha J, Hill M, Fanta M, Haakova L, VrbIkova J, Zivnya J. Prediction of insulin sensitivity in nonobese women with polycystic ovary syndrome. J Clin Endocrinol Metab. 2002 Dec;87 (12): 5821-5.

64. Ober KP. Acanthosis nigricans and insulin resistance associated with Hypothyroidism. Arch. Of Dermatology, 1985 (Feb); Vol.21 : No.2.

\section{RESULTS AND OBSERVATION:}

\begin{tabular}{|c|c|c|c|c|c|c|c|c|}
\hline \multirow{2}{*}{$\begin{array}{c}\text { Age } \\
\text { Group }\end{array}$} & \multicolumn{2}{|c|}{$\begin{array}{c}\text { Male } \\
\text { Controls }\end{array}$} & \multicolumn{2}{c|}{$\begin{array}{c}\text { Acanthosis } \\
\text { Nigricans }\end{array}$} & \multicolumn{2}{c|}{$\begin{array}{c}\text { Female } \\
\text { Controls }\end{array}$} & \multicolumn{2}{c|}{$\begin{array}{c}\text { Acanthosis } \\
\text { Nigricans }\end{array}$} \\
\cline { 2 - 9 } & $\mathbf{N}$ & $\mathbf{\%}$ & $\mathbf{N}$ & $\mathbf{\%}$ & $\mathbf{N}$ & $\mathbf{\%}$ & $\mathbf{n}$ & $\%$ \\
\hline $10-19$ & - & - & - & - & - & - & 7 & 23.2 \\
\hline $20-29$ & 3 & $30 \%$ & 4 & 13.3 & 2 & 20 & 4 & 13.3 \\
\hline $30-39$ & 1 & $10 \%$ & 2 & 6.6 & 1 & 10 & 5 & 16.6 \\
\hline $40-49$ & - & - & - & - & 1 & 10 & 1 & 3.3 \\
\hline $50-59$ & - & - & 1 & 3.3 & - & - & 1 & 3.3 \\
\hline BMI & & & & & & & & \\
\hline Non- Obese & 5 & 50 & 3 & 6.6 & 5 & 50 & 10 & 26.6 \\
\hline Obese & - & - & 6 & 23.3 & - & - & 11 & 43.3 \\
\hline W/H ratio & & & & & & & & \\
\hline$<0.8$ & - & - & - & - & 1 & 10 & - & - \\
\hline $0.7-1.0$ & 5 & 50 & 8 & 26.6 & 4 & 40 & 19 & 63.3 \\
\hline $1.1-1.15$ & - & - & 1 & 3.3 & - & - & 2 & 6.6 \\
\hline Table 1: Distribution of Study Population According to Age, Sex and Adiposity \\
\hline
\end{tabular}




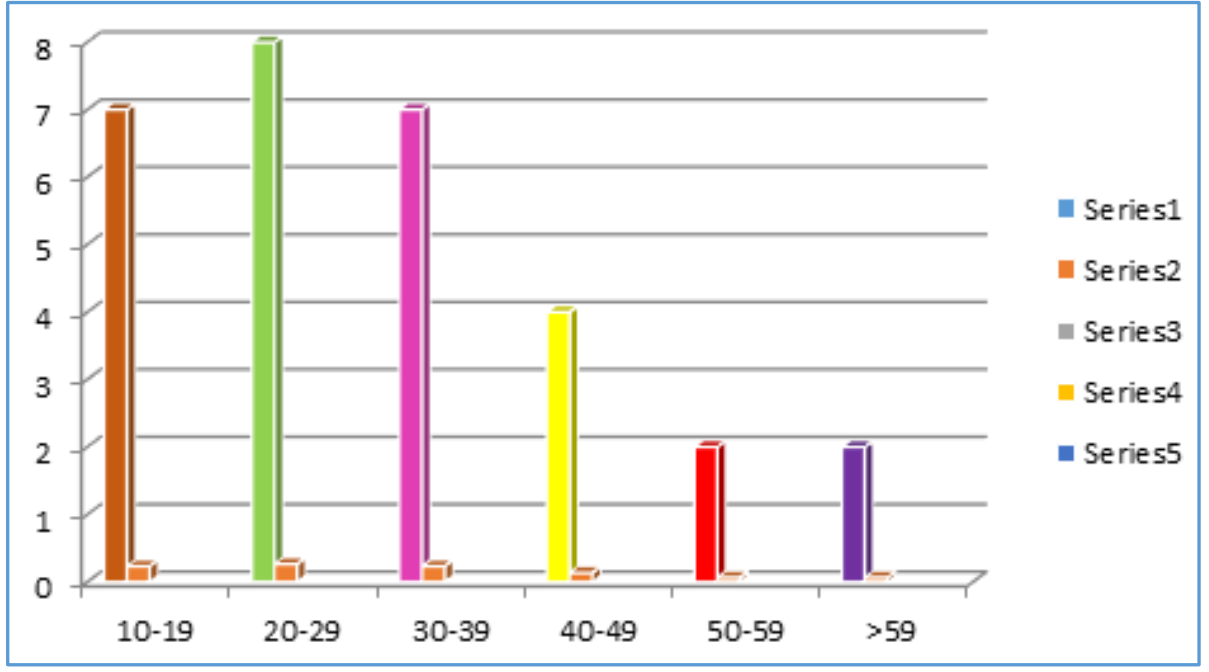

Fig.1: AGE DISTRIBUTION

\begin{tabular}{|c|c|c|}
\hline Age & No. & \% \\
\hline $10-19$ & 7 & $23.3 \%$ \\
\hline $20-29$ & 8 & $26.6 \%$ \\
\hline $30-39$ & 7 & $23.3 \%$ \\
\hline $40-49$ & 4 & $13.6 \%$ \\
\hline $50-59$ & 2 & $6.6 \%$ \\
\hline$>59$ & 2 & $6.6 \%$ \\
\hline Total & $\mathbf{3 0}$ & $\mathbf{1 0 0 \%}$ \\
\hline \multicolumn{2}{|c|}{ Table 1a: Age distribution (Disease group) } \\
\hline
\end{tabular}

More than half of the patients (52.9\%) were in the age group of 10-40 years.

\begin{tabular}{|c|c|c|}
\hline Age & No. & \% \\
\hline $10-19$ & 10 & 33.3 \\
\hline $20-29$ & 7 & 23.3 \\
\hline $30-39$ & 7 & 23.3 \\
\hline $40-49$ & 3 & 10.0 \\
\hline $50-59$ & 3 & 10.0 \\
\hline$>59$ & 0 & 0 \\
\hline Total & $\mathbf{3 0}$ & $\mathbf{1 0 0 \%}$ \\
\hline \multicolumn{2}{|c|}{ Table 2: Age of Onset } \\
\hline
\end{tabular}

The peak age of onset of the disease was between 10-19 years (33.3\%), followed by the age group between 20-40 years (23.3\%)

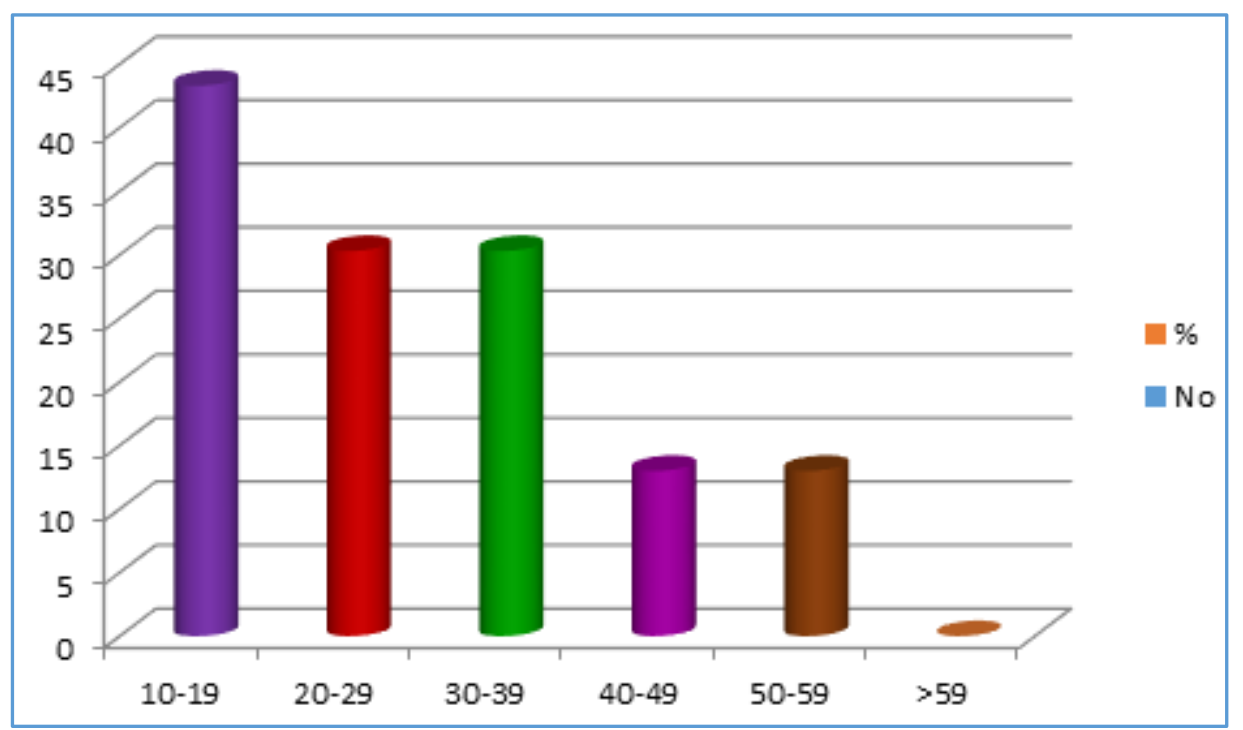

Fig. 2: AGE OF ONSET 


\begin{tabular}{|c|c|}
\hline Sex & \% \\
\hline Male & $30 \%$ \\
\hline Female & $70 \%$ \\
\hline Total & $\mathbf{1 0 0 \%}$ \\
\hline \multicolumn{2}{|c|}{ Table 3: Sex Distribution } \\
\hline
\end{tabular}

Out patients, 9 patients were males (30\%) and 21 patients were females (70\%).

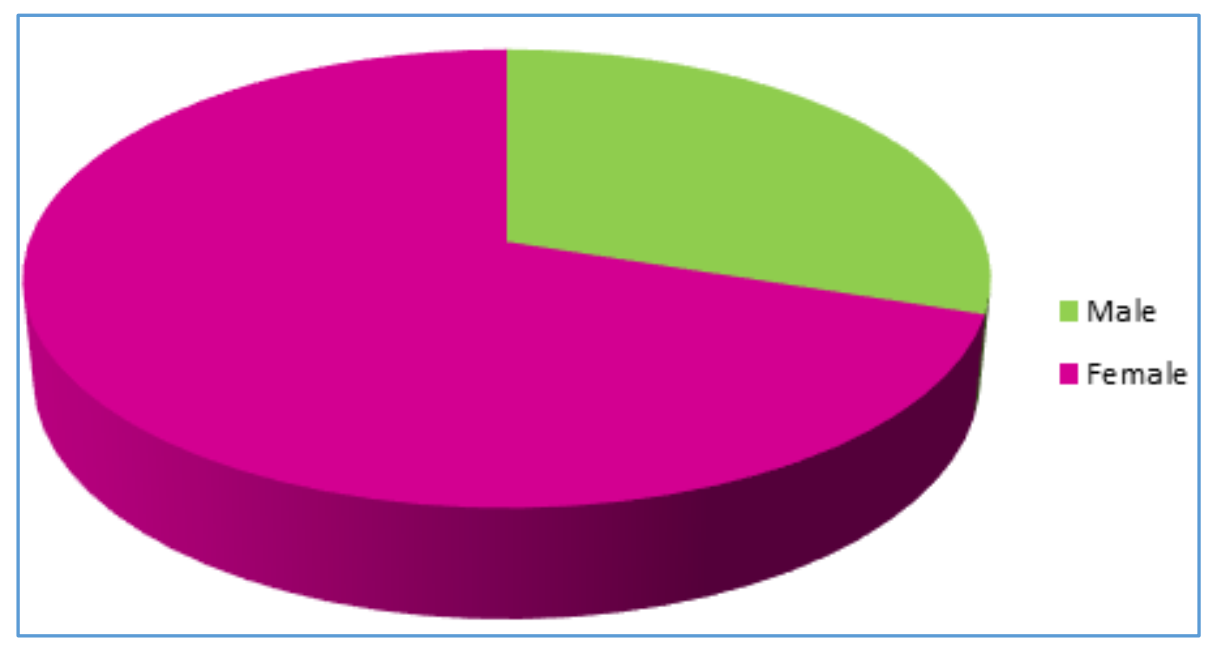

Fig. 3: SEX DISTRIBUTION

\begin{tabular}{|c|c|c|c|}
\hline \multirow{2}{*}{ Variable } & Group I (n=30) & Group II (n=10) & \multirow{2}{*}{ P- value* } \\
\cline { 2 - 3 } & Mean \pm S.D. & Mean \pm S.D. & $0.003(\mathrm{Sig})$ \\
\hline FBS & $122 \pm 60$ & $85 \pm 11$ & $<0.0001(\mathrm{Sig})$ \\
\hline SER- Insulin & $24.1 \pm 15.1$ & $10.9 \pm 3.7$ & $<0.0001(\mathrm{Sig})$ \\
\hline BMI & $32.9 \pm 6.2$ & $24.7 \pm 3.1$ & $0.31(\mathrm{NS})$ \\
\hline WHR & $0.30 \pm 0.10$ & $0.86 \pm 0.08$ & $0.02(\mathrm{Sig})$ \\
\hline QUICKI & $0.41 \pm 0.14$ & $0.53 \pm 0.10$ & $<0.0001(\mathrm{Sig})$ \\
\hline HOMA-IR & $147 \pm 138$ & $41 \pm 15$ & Group I And Group II \\
\hline \multicolumn{3}{|c|}{ Table 4: Mean, Standard Deviation and test of significance of Mean Values Between } \\
\hline
\end{tabular}

*Student's independent t-test was used to calculate the p-value.

\begin{tabular}{|c|c|c|c|c|c|}
\hline \multirow{2}{*}{ Variable } & $\begin{array}{c}\text { Obese } \\
(n=17)\end{array}$ & $\begin{array}{c}\text { Non-obese } \\
(n=13)\end{array}$ & $\begin{array}{l}\text { Control } \\
(n=10)\end{array}$ & \multirow[t]{2}{*}{ P-value* } & \multirow{2}{*}{$\begin{array}{c}\text { Significant } \\
\text { groups at } \\
5 \% \text { level }\end{array}$} \\
\hline & Mean \pm S.D. & Mean \pm S.D. & Mean \pm S.D. & & \\
\hline FBS & $137 \pm 67$ & $103 \pm 43$ & $85 \pm 11$ & $\begin{array}{l}0.04 \\
\text { (Sig) }\end{array}$ & $\begin{array}{c}\text { Obese vs } \\
\text { Control }\end{array}$ \\
\hline Ser-Insulin & $26.7 \pm 15.5$ & $20.8 \pm 14.3$ & $10.9 \pm 3.7$ & $\begin{array}{l}0.02 \\
\text { (Sig) } \\
\end{array}$ & $\begin{array}{c}\text { Obese vs } \\
\text { Control } \\
\end{array}$ \\
\hline BMI & $37.1 \pm 4.7$ & $27.4 \pm 2.1$ & $24.7 \pm 3.1$ & $\begin{array}{l}<0.0001 \\
\text { (Sig) }\end{array}$ & $\begin{array}{l}\text { Obese vs Non- } \\
\text { Obese, Control }\end{array}$ \\
\hline WHR & $0.92 \pm 0.12$ & $0.87 \pm 0.06$ & $0.86 \pm 0.08$ & $\begin{array}{l}0.24 \\
(\mathrm{NS})\end{array}$ & NIL \\
\hline QUICKI & $0.37 \pm 0.10$ & $0.45 \pm 0.18$ & $0.53 \pm 0.10$ & $\begin{array}{l}0.01 \\
\text { (Sig) }\end{array}$ & $\begin{array}{l}\text { Control vs } \\
\text { Obese }\end{array}$ \\
\hline HOMA-IR & $180 \pm 154$ & $104 \pm 105$ & $41 \pm 15$ & $\begin{array}{l}0.02 \\
\text { (Sig) }\end{array}$ & $\begin{array}{l}\text { Control vs } \\
\text { Obese }\end{array}$ \\
\hline
\end{tabular}

* One- way ANOVA was used to calculate the p-value

\# Multiple range test by Tulkey - HSD procedure was employed to identify the significant groups at 5\% level. 


\section{DURATION OF THE DISEASE}

The average duration noted in the present study was 5.8 years with a standard deviation of 10.40 .

\section{ASSOCIATED CONDITIONS}

\begin{tabular}{|c|c|c|c|c|c|}
\hline \multirow{2}{*}{ Obesity } & \multicolumn{2}{|c|}{ Male } & \multicolumn{2}{c|}{ Female } & \multirow{2}{*}{ p-value* } \\
\cline { 2 - 5 } & & $\%$ & No. & $\%$ & \\
\hline Yes & 6 & $66.7 \%$ & 11 & $54.4 \%$ & \\
\hline No & 3 & $33.3 \%$ & 10 & $47.6 \%$ & \\
\hline Total & 9 & $100 \%$ & 21 & 100 & 0.69 (NS) \\
\hline \multicolumn{6}{|c|}{ Table 6: Distribution of obesity by Gender } \\
\hline
\end{tabular}

*Fisher's exact test (2-tailed) was used to calculate the p-value.

\section{INFERENCE}

There is no significant difference in proportion of obesity between males and females $(\mathrm{p}=0.69)$.

OTHERS

\begin{tabular}{|c|c|c|c|c|}
\hline \multirow{2}{*}{ Obesity } & \multicolumn{2}{|c|}{ Male } & \multicolumn{2}{c|}{ Female } \\
\cline { 2 - 5 } & Number & \% & Number & \% \\
\hline Diabetes & 6 & 20 & 8 & 26.6 \\
\hline Hypertension & 3 & 10 & 4 & 13.3 \\
\hline Thyroid & 1 & 3.3 & 7 & 23.3 \\
\hline PCOD & 0 & 0 & 3 & 10 \\
\hline \multicolumn{7}{|c|}{ TABLE 7 } \\
\hline
\end{tabular}
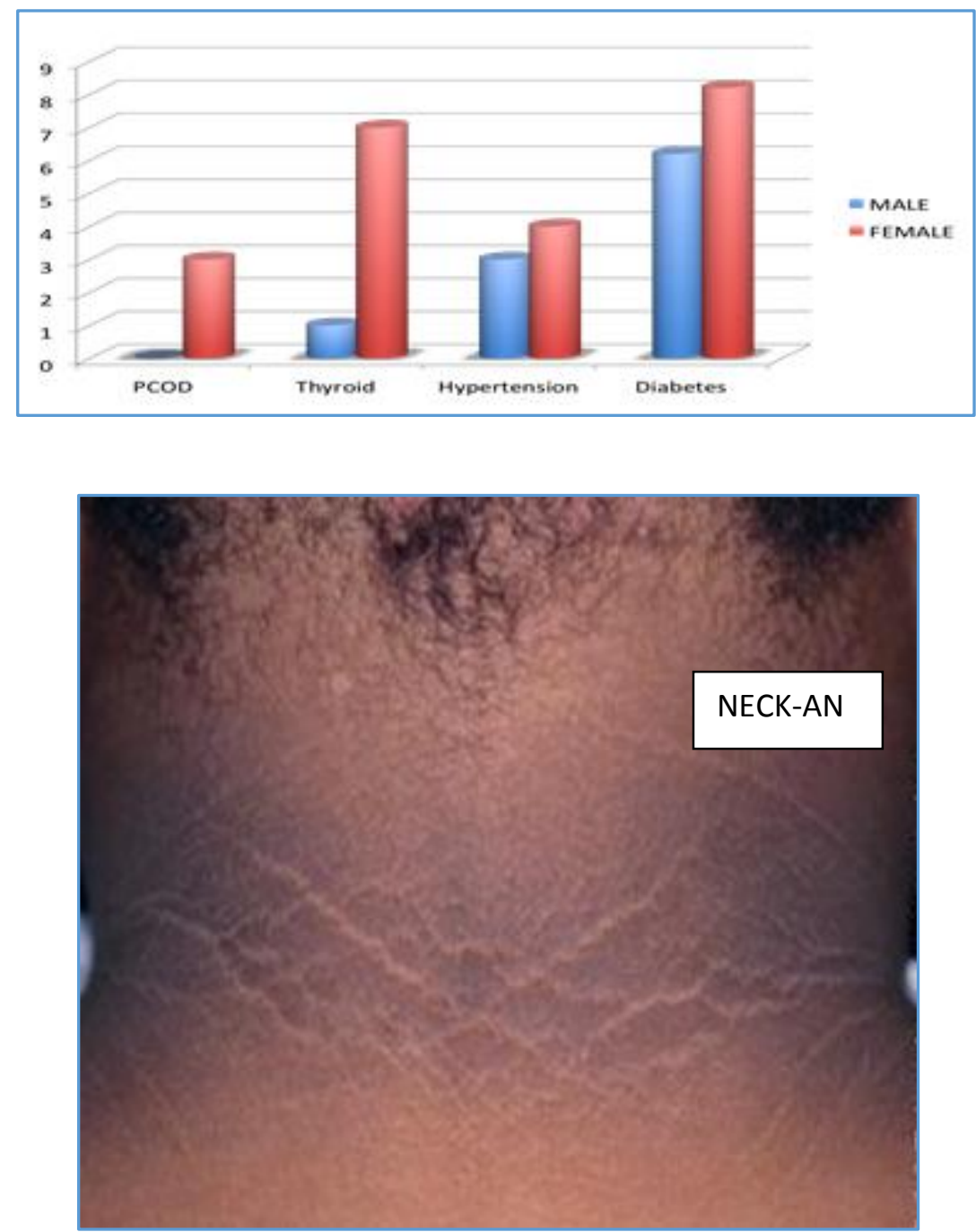

Fig. 4 


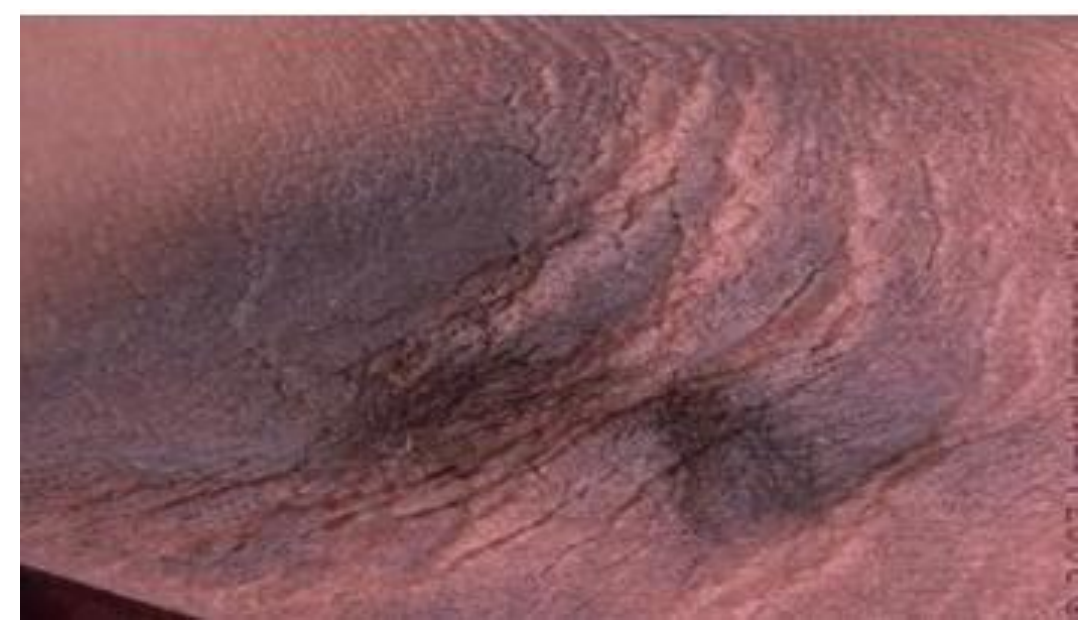

Fig. 5: Axilla - AN

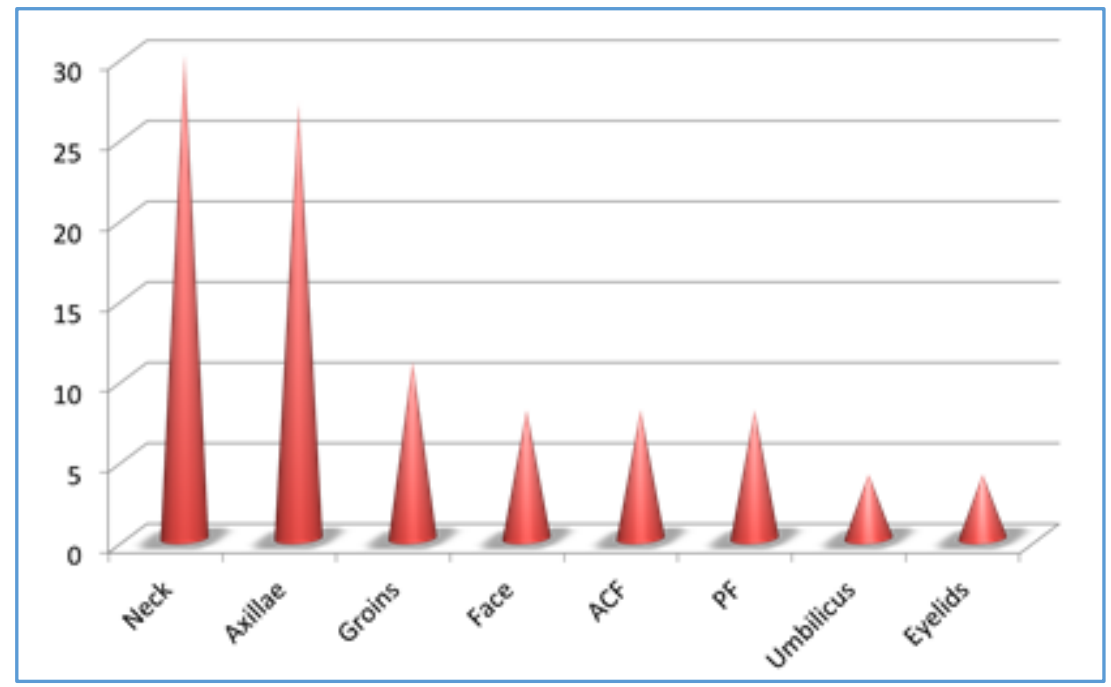

Fig. 6: SITES OF AN

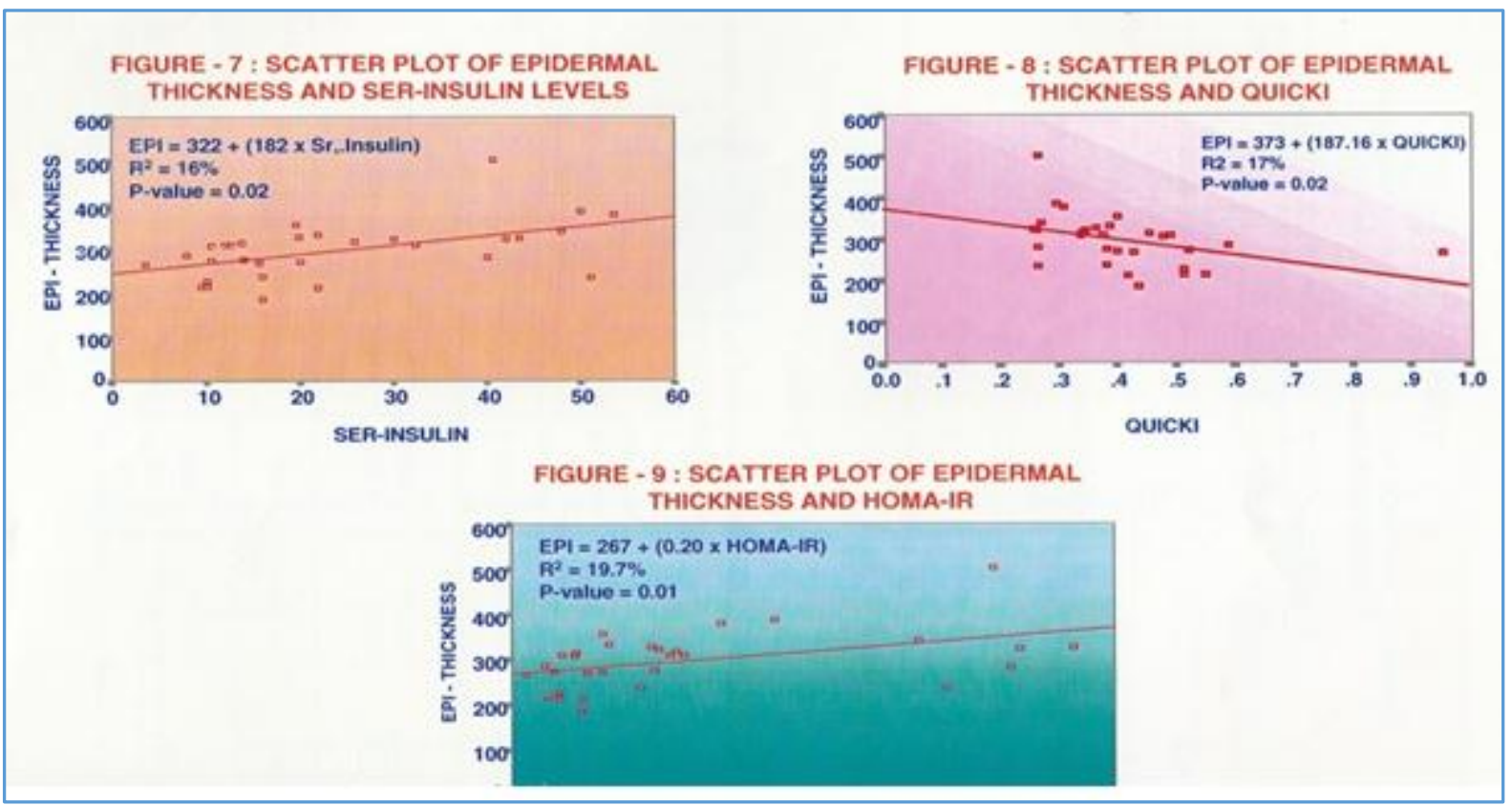



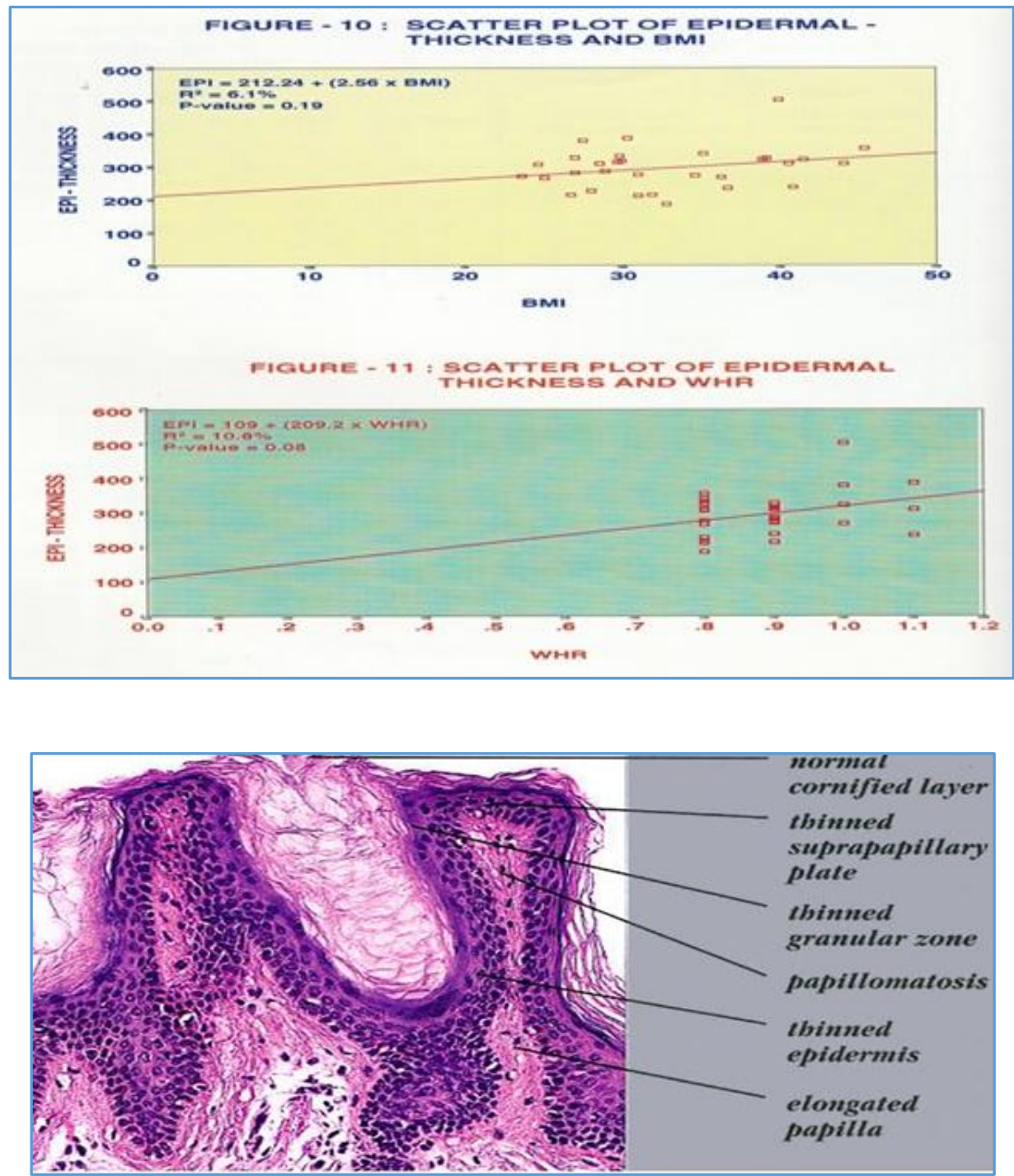

Fig. 12: HPE OF ACANTHOSIS NIGRICANS

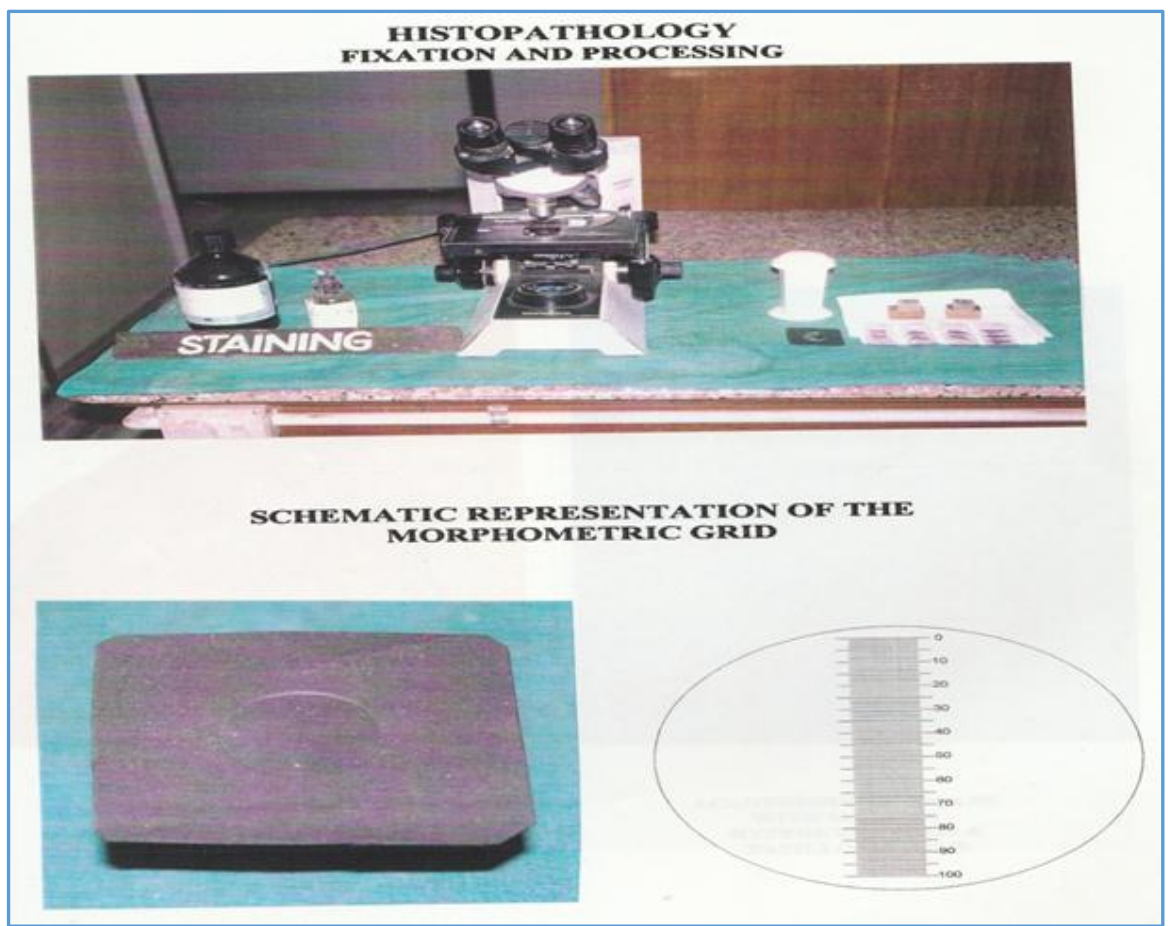

Fig. 13 